\title{
Tokat İlin'deki Uzun Yıllar Yağış Parametrelerinin CLIGEN Yağış Modeli ile Değerlendirilmesi
}

\author{
Saniye DEMIR ${ }^{1}$, İran OĞUZ², Ömer Faruk CiBA ${ }^{3}$
}

ÖZET: Bu çalışmada, Tokat meteoroloji istasyonundan 2005-2015 yıllarına ait günlük yağış verileri, CLIGEN yağış modeli kullanılarak tahmin edilmiştir. Gözlenen ve tahmin edilen günlük, aylık ve yıllık yağışların istatistiksel analizleri (ortalama, standart sapma, ve çarpıklık) karşılaştırılmıştır. Elde edilen sonuçlardan, gözlenen ve tahmin edilen yağış verileri arasındaki ilişkinin istatistiksel olarak önemsiz olduğu görülmüsştür. CLIGEN özellikle ilkbahar ve kış aylarında günlük yağış verilerini gözlenen değerin hafif altında tahmin etme eğilimdedir. Yıllık toplam ortalama ve aylık ortalama yağışları ise tahmin etmede oldukça yüksek bir performans göstermiştir.

Anahtar Kelimeler: CLIGEN, İklimsel değişiklikler, Tokat yağış

\section{Long Years Precipitation Parameters by CLIGEN Precipitation Model in Tokat Province}

\begin{abstract}
In this study, by using CLIGEN, between 2005-2015 long years historical daily precipitation records were simulated from Tokat weather stations. The basic statistics of daily, monthly and annual precipitations (mean, standart deviation, skewness) were compared with those derived from the observed and generated by CLIGEN weather series. The results showed no significant difference between observed and simulated values for rainfall parameters. Especially, CLIGEN estimations tend to underestimate the observed data in spring and winter months. CLIGEN exhibited higher performance in simulation of monthly and annual rainfall.
\end{abstract}

Keywords: CLIGEN, Climate variability, Tokat precipitations

\footnotetext{
Saniye DEMIR (0000-0003-3908-7070), Gazi Osman Paşa Üniversitesi, Ziraat Fakültesi, Toprak bilimi ve Bitki besleme , Tokat, Turkey İrfan OĞUZ (0000-0002-1576-333X), Gazi Osman Paşa Üniversitesi, Ziraat Fakültesi, Toprak Bilimi ve Bitki Besleme, Tokat, Turkey Ömer Faruk CİBA (0000-0001-8297-2855), 11. Bölge Müdürlüğü, Meteoroloji , Meteoroloji, Trabzon, Turkey Sorumlu yazar/Corresponding Author: Saniye DEMİR, saniye.demir@gop.edu.tr
} 


\section{GíRIŞ}

Hidrolojik, tarımsal ve ekolojik pek çok model uzun süreli günlük yağış verilerini kullanmak suretiyle toprak kayıplarını ve yüzey akışı tahmin etmektedir. Ancak, bu modellerin çalışması için gerekli gözlenen yağış veri setlerini oluşturmak çoğu zaman büyük bir problem olarak karşımıza çıkmaktadır. Çünkü, birçok bölgede yağış istasyonu bulunmamaktadır (Jones et al., 2003). Bundan dolay1, bu veriler ya eksik ya da hatalı olmaktadır. Yetersiz ya da hatalı verilerin bulunduğu bölgelerde yağış simülasyonu yapmak için, gözlenen verilerin istatistiksel değerleri göz önünde tutulmaktadır (Zhang, 2007). Günümüzde simülasyon yapan modeller kullanmak suretiyle, benzer iklim koşullarına sahip alanlarda yağış verilerinin simülasyonu yapılabilmektedir. (Fan et al,.2013).

The Water Erosion Prediction Project (WEPP) modelinin bir ara yüzü olarak geliştirilen CLIGEN, yağıŞ karakteristiklerinin simülasyonunda oldukça yaygın olarak kullanılan bir iklim modelidir (Nearing et al., 1989). CLIGEN ile hazırlanan iklim ara yüz dosyası ile yüzey akış ve toprak kayıpları tahmin edilmektedir. Özellikle CLIGEN' de simüle edilen yağış şiddetinin pik değeri, WEPP modelde yüzey akışın ve toprak kayıplarının hesaplanmasında çok önemli yer tutmaktadır (Elliot and Arnold, 2001).

CLIGEN ile iki grup yağış parametresi simüle edilmektedir. İlk grupta yağışın olup veya olmaması dikkate alınmadan günlük yağış miktarı, sıcaklık ve solar radyasyon yer alırken; ikinci grupta ise yağışlı günlere ait parametreler bulunmaktadır. Bu parametreler yağış, maksimum ve minumum sicaklık, solar radyasyon, rüzgarın şiddeti ve yönü ile çiğlenme noktasıdır.

CLIGEN iklim modeli dünyada yaygın olarak kullanılmaktadır. Johnson et al. (1996) Amerika Birleşik Devletlerinde altı farklı iklim koşullarında modeli değerlendirirken; Headrick and Wilson (1997) ise Minnesota eyaletinde beş farklı noktada benzer bir çalışma yapmıştır. Yapılan her iki çalışmada günlük yağışlara göre, maksimum ve minumum sicaklık ile solar radyasyon değerlerinin standart sapmalarının ayarlanması için bir yă̆ış olma ihtimali faktörünün kullanılması gerektiği ortaya çıkmıştır. Bu kalibrasyon ayarı ile sicaklık ve solar radyasyon değerindeki değişimin azalacağı kabul edilmiştir. Türkiye'de, yağış verilerinin değerlendirilmesinde CLIGEN yaygın olarak kullanılmamaktadır. Türkiye'nin her bir bölgesinde görülen iklim karakteristikleri birbirinden farklıdır ve bu bölgelerin birçoğu coğrafik özellikleri bakımından erozyona oldukça sık maruz kalmaktadır. Toprak-su koruma açısından her bir bölgenin iklim özelliklerinin değerlendirilip, toprak ve yüzey akış ile ilişkilendirilmesi gelecekte yapılacak çalışmalar için önem taşımaktadır. Bu çalışmada, Tokat iline ait 2005-2015 yılları arasındaki iklim verilerinin CLIGEN ile simülasyonu yapılmak suretiyle, elde edilen ve gözlenen günlük, aylık ve yıllık yağış verileri karşılaştırılarak modelin Tokat iklim koşulları altında performansının değerlendirilmesi amaçlanmaktadır.

\section{MATERYAL VE YÖNTEM}

\section{Çalışma Alanı}

CLIGEN'in performansının değerlendirildiği Tokat ili, Orta Karadeniz bölümünün iç kısımlarında yer almakta olup, Karadeniz iklim özellikleriyle İç Anadolu'daki step (kara) iklimin etkisi altındadır. 2005-2015 yılları arasındaki Tokat Meteoroloji istasyonu kayıtları esas alındığında yıllık ortalama sıcaklık $14{ }^{\circ} \mathrm{C}$, yıllık yağışlar $479 \mathrm{~mm}$ ile $241.50 \mathrm{~mm}$ arasında değişmekte olup, en fazla yağış ilkbahar ve en az yağış ise yaz mevsiminde görülmektedir (DMI, 2015). Bu değerlere göre toprak sıcaklık rejimi Mesic ve nem rejimi ise Ustic olarak sınıflandırılmaktadır (Soil Survey Staff, 2009).

\section{Yöntem}

Tokat iline ait 2005-2015 yılları arasındaki günlük, aylık ve yıllık yăğıs verilerinin simülasyonu için CLIGEN iklim modeli kullanılmıştır. Günlük veriler 11 yıllık zaman dilimindeki bireysel yağış olaylarından; aylık veriler, bu zaman dilimine ait her bir ay içindeki

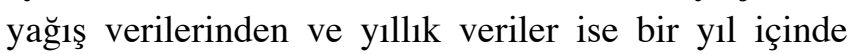
görülen yağış olaylarından oluşturulmuştur.

\section{CLIGEN iklim modeli}

The Water Erosion Prediction Project (WEPP) modelinin ara yüzünü oluşturan CLIGEN erozyon, hidroloji, günlük su dengesi, bitki büyümesi ve atıkların ayrışması gibi pek çok parametreyi hesaplamak için yağış karakteristiklerini simüle etmektedir (Nicks et al., 1995). Bu yağış karakteristikleri günlük yağış, maksimum ve minumum sicaklık, çiğlenme noktası, solar radyasyon, rüzgar şiddeti ve hızıdır. 
$\mathrm{Bu}$ çalışmada verilerin simülasyonunun ilk basamağını iki durumlu Markov Zinciri oluşturmaktadır. $\mathrm{Bu}$ yöntem ile sslak ve kuru günlerin tayini yapılmaktadır. Yă̆ışılı bir günü yağışlı bir günün izleme

$$
P(W / W)=\frac{N w w}{N d w+N w w} \quad \text { ve } \quad P\left(W / D=\frac{N d w}{N w d+N d d}\right.
$$

Formülleri kullanılmaktadır. Burada;

Nww: Islak bir günden sonra sslak olma ihtimali

Nwd: Islak bir günden sonra kuru olma ihtimali

Ndw:Kuru bir günden sonra 1slak olma ihtimali

Ndd: Kuru bir günden sonra kuru olma ihtimali

Ekstrem yağış olaylarını tanımlamak için, bireysel yağışlara ait eşik değer kullanmak suretiyle yüksek ve

$x=\frac{6}{g}\left(\left(\left(\frac{g}{2} * \frac{X-u}{s}\right)+1\right)^{1 / 3}-1\right) * \frac{g}{6}$
$\mathrm{x}$ : Random değişken
u: Aylık ortalama yağış değeri
s: Aylık yağışların standart sapma değeri
g: Aylık yağışların çarpıklık değeri

$\mathrm{X}$ : Simüle edilen yağış

\section{İstatistiksel analizler}

Çalışmada, CLIGEN'e girilen 11 yıllık her bir iklim veri setinin basit istatistiksel analizleri yapılmıştır. Ortalama, standart sapma ve çarpıklık katsayıları belirlenmiştir. Ancak, Zhang et al. (2008) yapmış olduğu

\section{BULGULAR VE TARTIŞMA}

\section{Günlük Yağış Verilerinin Değerlendirilmesi}

Tokat iline ait 11 yıllık gözlenen ve simüle edilen bireysel yağış olayları karşılaştırılmış ve sonuçlar Şekil 1 ve Şekil 2'de gösterilmiştir. CLIGEN iklim modeline 2005-2015 yıllar1 arasında 561 bireysel yağış olayı girilmiştir. Gözlenen ve simüle edilen bireysel yağış olayları arasındaki ilişkiyi gösteren ihtimali $\mathrm{P}(\mathrm{W} / \mathrm{W})$ ve yağışlı bir günü kuru günün izleme ihtimali ise $\mathrm{P}(\mathrm{W} / \mathrm{D})$ olarak ifade edilmektedir. Bu her iki olay dönüşüm ihtimali olarak isimlendirilmektedir. Dönüşüm ihtimallerinin belirlenmesinde; düşük yağışlar hesaplanmıştır. Yüksek yağışlar için $\% 75$ ve düşük yağışlar için ise \%25 değeri alınmıştır. CLIGEN yağış verilerinin simülasyonunda, her aya ait günlük yağış verilerinin ortalama, standart sapma ve çarpıklık değerlerini kullanmaktadır. Bir günün yă̆ış̧ı ya da kuru olduğu Markov Zincirine göre belirlendikten sonra random değişkenler belirlenmektedir. Bir sslak güne ait yağış miktarı ise normal (çarpık) dağılıma dönüş̧türülerek, Eşitlik 2. ile yağış hesaplaması yapılmaktadır. çalışmada belirttiği gibi, yağış parametreleri normal dağılım göstermemektedir. Bundan dolayı aralarındaki ilişkiyi belirlemek için Kolmogorov-Smirnov (K-S testi) ve Mann-Whitney (M-W testi) (Mann, 1945) nonparametrik istatistiksel analizler yapılmıştır.

grafik incelendiğginde (Şekil 2), aralarında yüksek bir ilişkinin bulunmadığ 1 ve verilerin büyük bir kısmının 1:1 hattına yakın ve altında dağılım gösterdiği görülmektedir ( $\left.\mathrm{R}^{2}: 0.67\right)$. CLIGEN, özellikle yüksek değerli bireysel yağış olaylarını gözlenen değerin altında tahmin etmiştir. Çalışma yöresine ait CLIGEN ile bulunan bu sonuçlar, yüksek yağış miktarlarına bağlı bireysel toprak kayıplarını hesaplamada göz önünde bulundurulması bölgede yapılacak toprak-su 
koruma açısından yararlı olacağ 1 düşünülmektedir. Min et al. (2011), Kore'de 8 farklı eyalette 55 yıllık iklim verilerinin CLIGEN ile simülasyonunu yapmışlardır. Eyaletlerin dördünde modelin bireysel yağışları tahmin etmede çok başarılı olmadığı ve gözlenen değerlerin altında tahminlerde bulunduğu gözlenmiştir. Zhang and Garbrecht (2003) bireysel yağış olaylarını gözlenen değerin altında tahmin etmişlerdir. Wilk's (1999), yağış verilerinin oldukça yüksek değişkenlik göstermesinden dolayı, modelin altında tahminlerde bulunabileceğini yapmış olduğu çalışmada ifade etmiştir

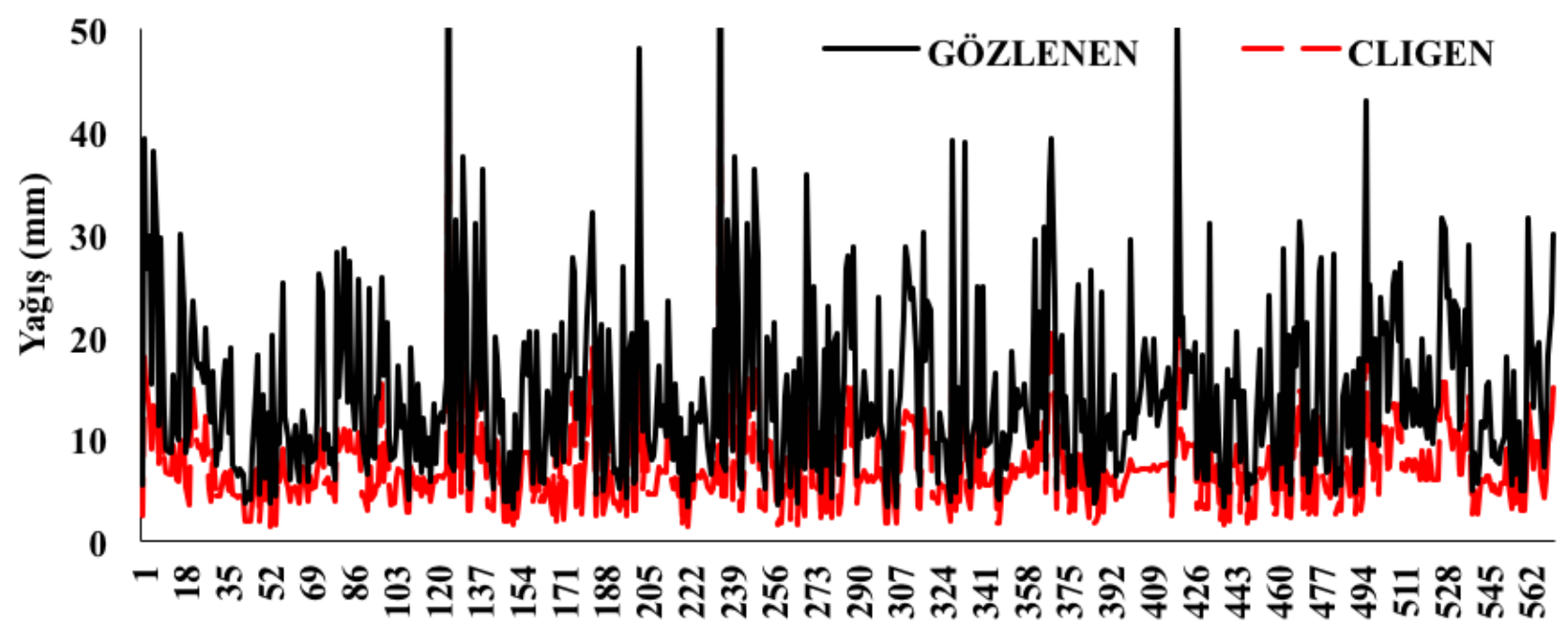

Şekil 1.Bireysel Yağış Olaylarının Grafiksel Olarak Karşılaştırılması

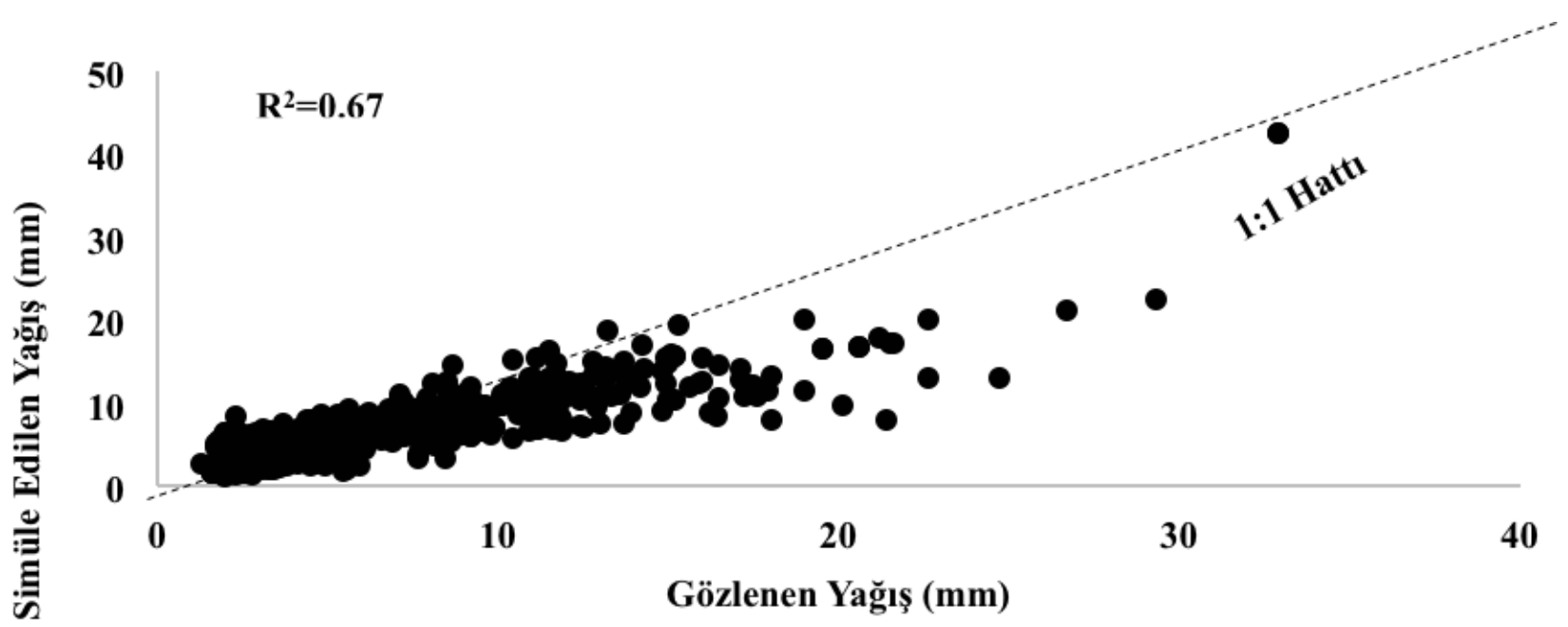

Şekil 2. Bireysel Yağış Olayları Arasındaki İlişki

Günlük bireysel yağış olaylarının tanımlayıcı istatistikleri yapılmış ve bulunan sonuçlar Çizelge 1 'de verilmiştir. Gözlenen ve simüle edilen bireysel yağış olaylarını aritmetik ortalaması sırasıyla 7.45 ve $7.22 \mathrm{~mm}$ olarak belirlenmiştir. Aritmetik ortalamaların aynı olmasına rağmen veriler, aynı yaygınlıkta dağ 1 lım göstermemektedir. $\mathrm{Bu}$ durum verilerin ortalamaya yakın ya da uzak dağılım göstermeleri ile ilişkilidir. Çalışma döneminde CLIGEN'e girilen
131 günlük bireysel yağış olayı 11-33 mm arasında değişmekte olup; bu değerler ortalamadan uzak bir dağılım göstermektedir. Gözlenen ve simüle edilen bireysel yağış verilerinin standart sapma değerleri ise 4.94 ve 4.29 'dur (Çizelge 1). Genel olarak standart sapma değeri, verilerin aritmetik ortalama etrafındaki dağılımın göstergesidir. Küçük değerler ortalamalardan sapmaların ve riskin az olduğunu, büyük değerler ise ortalamalardan sapmaların ve riskin yüksek olduğunu 
ifade etmektedir. Bulunan standart sapma değerleri yüksek olup, ortalamalardan sapma ve risk yüksektir. Gerek gözlenen ve gerekse simüle edilen günlük yağış değerlerine ait ortalama yağış ve standart sapma değerleri dikkate alındığında günlük yă̆ışlar için yüksek varyasyon söz konusudur.

Çizelge 1. Gözlenen ve simüle edilen bireysel yağışlara ait tanımlayıcı istatistiksel analizler

\begin{tabular}{|c|c|c|c|c|c|c|}
\hline $\begin{array}{l}\text { İstatistiksel } \\
\text { Analizler }\end{array}$ & $\begin{array}{c}\text { Ortalama } \\
\text { Yağıș (mm) }\end{array}$ & $\begin{array}{c}\text { Yağış } \\
\text { Standart } \\
\text { Sapma }\end{array}$ & $\begin{array}{c}\text { Varyasyon } \\
\text { Katsayısı }\end{array}$ & $\begin{array}{c}\text { Yağıs } \\
\text { Çarpıklık }\end{array}$ & M-W & K-S \\
\hline $\begin{array}{c}\text { Gözlenen } \\
\text { Yağışlar }\end{array}$ & 7.45 & 4.94 & 66,30 & 1.57 & \multirow[b]{2}{*}{0.073} & \multirow[b]{2}{*}{0.139} \\
\hline $\begin{array}{c}\text { Simüle Edilen } \\
\text { Yağışlar }\end{array}$ & 7.22 & 4.29 & 59.42 & 2.54 & & \\
\hline
\end{tabular}

Çalışmada kullanılan veri setine ait çarpıklık değerleri sırasıyla 1.57 ve 2.54 'dür (Çizelge 1). Veriler sağa çarpık bir dağılım göstermektedir ki bu değerler; modelin tahmin etmede ki performansının çok iyi olmadı̆̆ını göstermektedir.

Aralarındaki farklılığı belirlemek için nonparametrik istatistiksel analizler yapılmıştır. $\mathrm{Bu}$ analizlerden Kolmogorov-Smirnov (K-S testi) ve Mann-Whitney (M-W testi) testine göre bulunan sonuçlar verilmiştir (Çizelge 1). K-S testinde 0.073 ve $\mathrm{M}-\mathrm{W}$ testinde ise 0.139 olarak bulunmuş olup, gözlenen ve simüle edilen bireysel yağ $1 S ̧$ verileri arasında $\mathrm{p}=0.05$ düzeyinde önemli bir fark olmadığı ve aynı popülasyondan geldiği görülmüştür (Çizelge 1).

\section{Aylık Yağış Verilerinin Değerlendirilmesi}

Aylık yağış verilerinin değerlendirilmesinde, 2005-2015 yılları arasındaki 11 yılın her bir ayına ait gözlenen ve tahmin edilen yağış verileri kullanılmış ve sonuçlar Şekil 3'te grafiksel olarak gösterilmiştir. Çalışma alanında kullanılan zaman dilimi içinde ağustos ayında hiç yağış gözlenmemiştir. En fazla yağış ilkbahar mevsiminde (mart, nisan, mayıs) ve en az yağış ise yaz (haziran, temmuz, ağustos) aylarında gözlenmiştir (Şekil 3). En fazla yağışlar ekim ve mayıs ayında meydana gelmiştir. Tokat ili, Orta Karadeniz Geçit Kuşağında yer almaktadır. Özellikle, sonbahar aylarında Karadeniz'de görülen fırtınalardan oldukça etkilenmektedir. Mayıs ayı ise, kış mevsiminden yaz mevsimine geçişin olduğu zaman aralığındadır. Bu ay içinde kar erimeleri, ekstrem yağışlar çok sık görülmektedir. Temmuz ayı yaz mevsiminde olmasından dolayı yağışların nadiren olduğu bir aydır. Bu ayda extrem yağışlar görülmektedir. Bu yağışlar, ay içerisinde meydana gelen yağışların şiddetini doğrudan etkilemektedir ve yağış olayların karşılaştırılmasında sapmalara yol açmaktadır. Min et al. (2011) yapmış olduğu çalışmada, yaz aylarıyla ilgili olarak benzer sonuçları bulmuştur. Ocak ve kasım ayındaki yağışları gözlenen değerin altında tahmin ederken, eylül ayındaki yă̆ışları yüksek tahmin etmiştir. $\mathrm{Bu}$ aylarda görülen eksterm yağışlardan dolayı, standart sapma yükselmekte ve modelin tahmin etme başarısı düşmektedir. Kou et al. (2007), Çin'de 30 yıllık iklim verilerini kullanarak yapmış olduğu çalışmada, modelin yaz ayına göre kış ve sonbahar aylarındaki performansının daha yüksek olduğunu, modelin aylık toplam yağış ve ıslak günleri, gözlenen değerlere çok yakın tahmin ettiğini ifade etmişlerdir. Diğer aylar için CLIGEN ile simüle edilen aylık yağışlar, gözlenen değerlere yakın bulunmuştur (Şekil 3). Yağış verilerinin dağılımı birbirine oldukça yakındır ve veriler ortalamaya yakın bir dağılım göstermektedir. Bundan dolayı, modelin aylık yağışları tahmin etme performansı daha yüksek olmaktadır. 

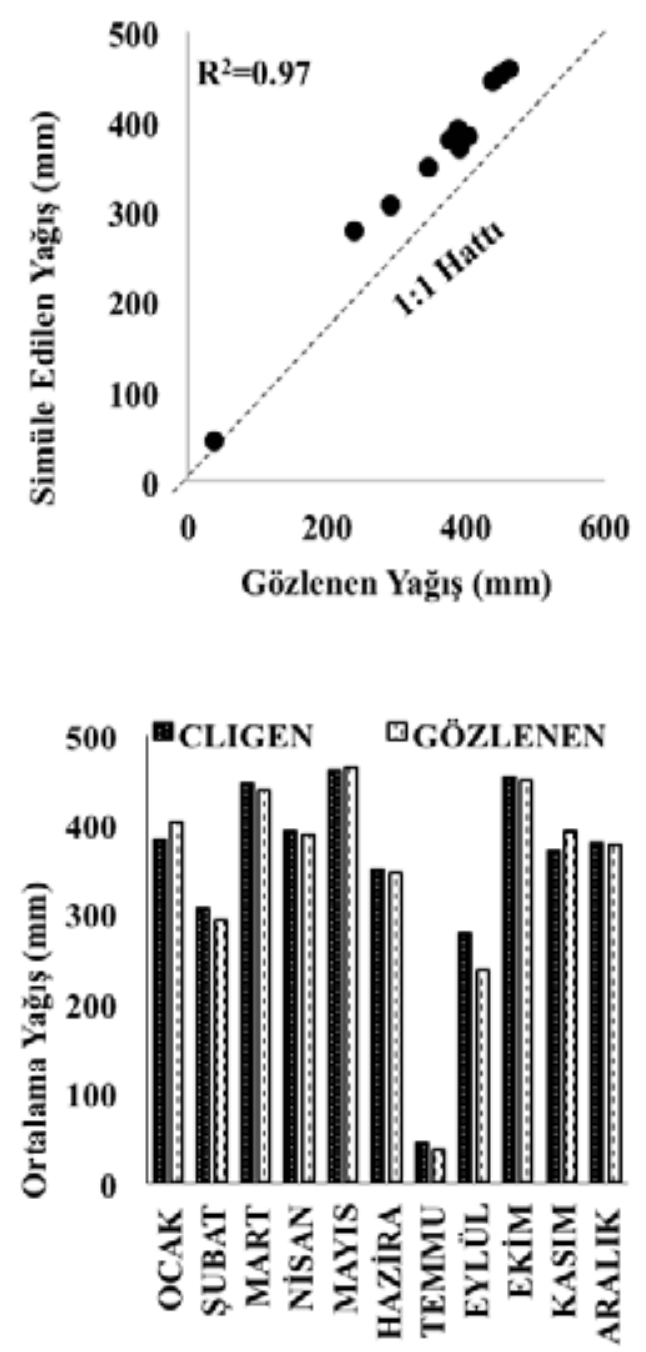

Şekil 3. Aylık Toplam Yağışların Grafiksel Olarak Karşılaştırılması

Gözlenen aylık yağış verileri $X$ eksenine ve simüle edilen aylık yă̆gşlar ise $\mathrm{Y}$ eksenine yerleştirilerek aralarındaki korelasyon ilişkisi belirlenmiştir (Şekil 3). Şekil 3 incelendiğinde, veriler 1:1 hattı boyunca dağılım göstermekte, model aylık toplam yağışları gözlenen değerlere yakın tahmin etmekte, aralarındaki ilişki ise oldukça yüksek ( $\left.\mathrm{R}^{2}: 0.97\right)$ olduğu görülmektedir.

Aylık yağışlara ait veri setindeki yağışların ortalama, standart sapma ve çarpıklık katsayıları belirlenmiş ve bulunan sonuçlar Çizelge 2'de verilmiştir. Gözlenen ve simüle edilen yağış verilerinin ortalaması $6 \mathrm{~mm}$ civarındadır. Ancak temmuz ayında bu değer 12.23-14.74 mm olarak belirlenmiştir. Eylül, ekim, kasım ve aralık ayı için ortalama değer yükselmiştir (Çizelge 2). Çünkü bu aylarda ekstrem yağışlar çok sık aralıklarla meydana gelmektedir. Yağış verilerinin standart sapması 3 ila
6 arasında değişmektedir. Veriler ortalamaya yakın bir yayılım göstermektedir. Özellikle tahmin edilen verilerin standart sapmaları gözlenen değerden daha düşüktür. Bunun nedeni, model simülasyon yaparken normalleştirilmiş veri kullanmasıdır. Çarpıklık katsayıları ise 0 ile 1 yakın değerler arasında değişmektedir. Bulunan bu değerler, verilerin normal bir dağılım gösterdiğini ve modelin tahmin etmedeki başarısının oldukça yüksek olduğunu göstermektedir (Çizelge 2).

Aylık yağış veri setinin normal dağılım gösterip göstermedikleri Kolmogorov-Smirnov (K-S testi) ve aralarındaki farklılık olup olmadı $\breve{g} 1$ ise MannWhitney (M-W testi) istatistiksel analizler kullanılarak belirlenmiştir (Çizelge 3). Çizelge 3'de görüldüğüü üzere veriler normal dağılım göstermekte ve aralarındaki ilişki önemsizdir (p:0.005 düzeyinde). 
Çizelge 2. Gözlenen ve simüle edilen aylık yağışlara ait tanımlayıcı istatistiksel analizler

\begin{tabular}{|c|c|c|c|}
\hline Aylar & Tanımlayıcı İstatistikler & Gözlenen Yağış (mm) & Simüle Edilen Yağış (mm) \\
\hline \multirow{3}{*}{ OCAK } & Ortalama & 6.00 & 5.71 \\
\hline & Standart Sapma & 4.11 & 3.18 \\
\hline & Çarpıklık & 1.02 & 0.61 \\
\hline \multirow{3}{*}{ ŞUBAT } & Ortalama & 6.63 & 6.95 \\
\hline & Standart Sapma & 5.40 & 4.33 \\
\hline & Çarpıklık & 1.74 & 1.25 \\
\hline \multirow{3}{*}{ MART } & Ortalama & 6.54 & 6.63 \\
\hline & Standart Sapma & 5.48 & 3.35 \\
\hline & Çarpıklık & 1.61 & 1.14 \\
\hline \multirow{3}{*}{ NISAN } & Ortalama & 6.46 & 6.52 \\
\hline & Standart Sapma & 3.93 & 3.09 \\
\hline & Çarpıklık & 1.21 & 1.14 \\
\hline \multirow{3}{*}{ MAYIS } & Ortalama & 6.91 & 6.85 \\
\hline & Standart Sapma & 3.83 & 2.35 \\
\hline & Çarpıklık & 1.40 & 0.47 \\
\hline \multirow{3}{*}{ HAZİRAN } & Ortalama & 6.95 & 6.98 \\
\hline & Standart Sapma & 3.93 & 2.80 \\
\hline & Çarpıklık & 1.08 & 0.36 \\
\hline \multirow{3}{*}{ TEMMUZ } & Ortalama & 12.23 & 14.74 \\
\hline & Standart Sapma & 8.71 & 8.78 \\
\hline & Çarpıklık & -1.38 & -1.72 \\
\hline \multirow{3}{*}{ EYLÜL } & Ortalama & 9.52 & 11.13 \\
\hline & Standart Sapma & 9.54 & 12.64 \\
\hline & Çarpıklık & 1.85 & 1.96 \\
\hline \multirow{3}{*}{ EKİM } & Ortalama & 8.99 & 9.05 \\
\hline & Standart Sapma & 4.91 & 4.24 \\
\hline & Çarpıklık & 0.03 & -0.18 \\
\hline \multirow{3}{*}{ KASIM } & Ortalama & 7.86 & 7.40 \\
\hline & Standart Sapma & 6.13 & 5.02 \\
\hline & Çarpıklık & 1.46 & 1.05 \\
\hline \multirow{3}{*}{ ARALIK } & Ortalama & 7.39 & 7.44 \\
\hline & Standart Sapma & 4.82 & 4.23 \\
\hline & Çarpıklık & 1.41 & 0.78 \\
\hline
\end{tabular}


Saniye DEMIR ve Ark.

Çizelge 3. Aylık yağış verilerinin normalite analizleri

\begin{tabular}{lccccccccccc}
\hline Aylar & Ocak & Şubat & Mart & Nisan & Mayıs & Haziran & Temmuz & Eylül & Ekim & Kasım & Aralık \\
\hline M-W & 0.693 & 0.620 & 0.271 & 0.123 & 0.767 & 0.465 & 0.564 & 0.863 & 0.976 & 0.398 & 0.497 \\
\hline K-S & 0.275 & 0.081 & 0.394 & 0.052 & 0.574 & 0.624 & 0.540 & 0.171 & 0.418 & 0.811 & 0.063 \\
\hline
\end{tabular}
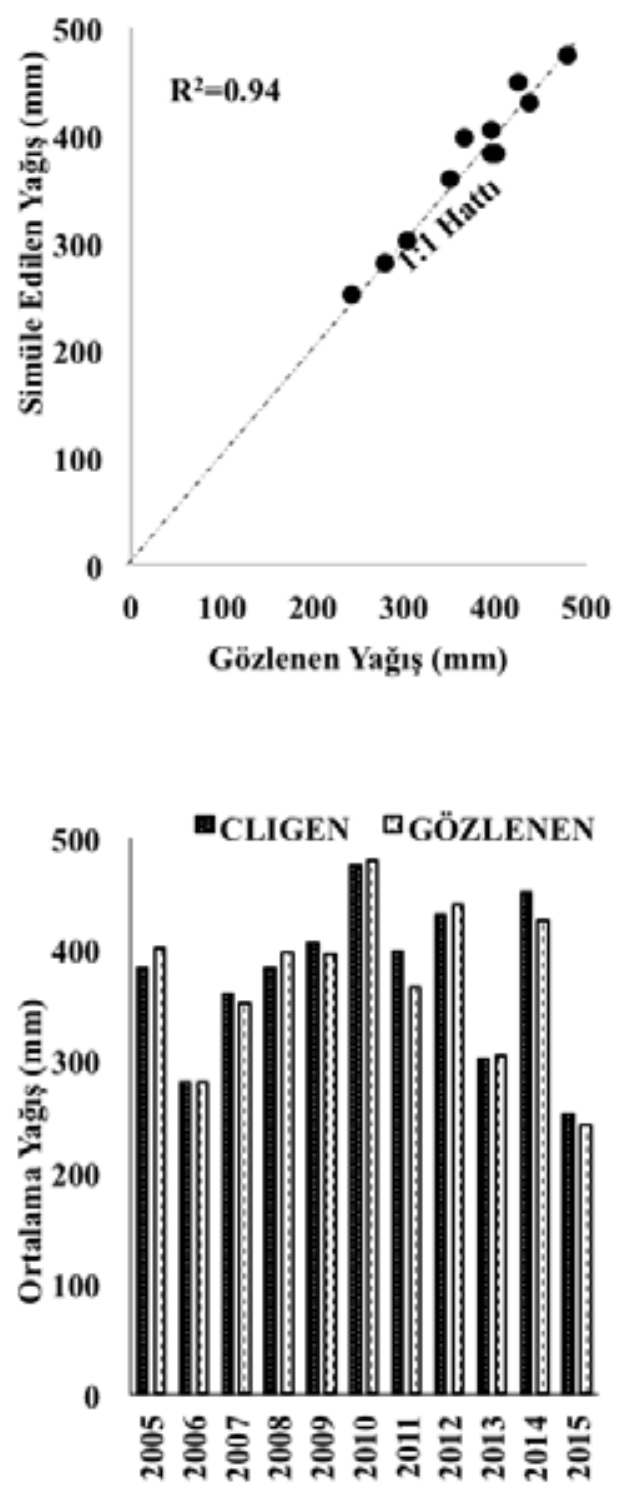

Şekil 4.Yıllık Toplam Yağışların Grafiksel Olarak Karşılaştırılması

\section{Yıllık Yağış Verilerinin Değerlendirilmesi}

Gözlenen ve simüle edilen yıllık toplam yă̆ışlara ait ilişki Şekil 4'de verilmiştir. Model, aylık yă̆gşlarda olduğu üzere yıllık toplam yağışları simüle etmede oldukça başarılıdır. 2005-2015 yılları arasındaki zaman diliminde, model 2005 yılındaki yă̆ışları düşük, 2014 yılındaki yağışları ise gözlenen değerden yüksek tahmin ederken; diğer yıllar için hemen hemen gözlenen değere yakın veya çok az üzerinde tahminde bulunmuştur. En fazla toplam yağış 2010 yılında meydana gelirken, en düşük yağış ise 2015 yılında görülmüştür. Tokat 
ilinde, 2007-2009 yılları arasında gözlenen ve tahmin edilen yağışların 400 mm'ye yakın olduğu gözlenirken, 2010-2012 ve 2014 yıllarında bu değer 400 mm'nin üzerine çıkmıştır (Şekil 4). Gözlenen ve simüle edilen yıllık toplam yağış verileri arasındaki ilişki Şekil 4'de grafiksel olarak gösterilmiştir. Şekil 4 incelendiğinde verilerin 1:1 hattının biraz üzerinde ve 1:1 hattına

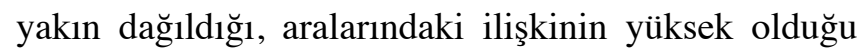
$\left(\mathrm{R}^{2}: 0.94\right)$ olduğu görülmektedir. Gözlenen ve simüle edilen yıllık toplam yağışlara ait tanımlayıcı istatistiksel analizler Çizelge 4'de verilmiştir. Yıllık toplam yağışların ortalaması, aylık yağışlarda olduğu gibi 6-7 mm civarında bir dağılım göstermektedir. Ancak, yıllık yağış verilerinin standart sapma ve çarpıklık katsayısı aylık yağgş̧ verilerinden daha yüksek bulunmuştur (Çizelge 4). Bu duruma, yıl içerisinde özellikle ilkbahar aylarında görülen ekstrem yağışlar neden olmaktadır. Verilerin standart sapma ve çarpıklık katsayısının yüksek olmasından dolayı, log transformasyon yapılmak suretiyle yağış verileri normale yakın bir yayılım aralığında dağılım göstermiştir (Çizelge 4).

2009 y1lı hariç, model diğer 10 yılın standart sapmalarını gözlenen değerin altında tahmin ederken; bu yıla ait standart sapma değerini yüksek tahmin etmiştir. Kou et al. (2007) Çin'in beş farklı eyaletinde, CLIGEN modelinin validasyonu için çalışma yapmıştır. Çalışmada kullanılan yağış verilerinin standart sapma değerinin yüksek olmasından dolayı log transformasyon yapılmıştır. Çalışmanın sonucunda, beş eyaletinde dördünde model yağış verilerinin standart sapma değerini gözlenen değerin altında tahmin ettiği görülmüştür. Yağış verileri arasındaki ilişkinin önemli olup olmadığı M-W testiyle istatistiksel olarak değerlendirilmiş (Çizelge 5) ve aralarındaki ilişkinin önemsiz olduğu belirlenmiştir $(\mathrm{p}<0.05)$.

Çizelge 4. Gözlenen ve simüle edilen yıllık yağışlara ait tanımlayıcı istatistiksel analizler

\begin{tabular}{|c|c|c|c|}
\hline Yillar & Tanımlayıcı İstatistikler & Gözlenen YağıŞ（mm) & Simüle Edilen YağıŞ (mm) \\
\hline \multirow{3}{*}{2005} & Ortalama & 7.77 & 8.21 \\
\hline & Standart Sapma & 4.32 & 3.72 \\
\hline & Çarpıklık & 0.95 & 0.80 \\
\hline \multirow{3}{*}{2006} & Ortalama & 7.77 & 8.21 \\
\hline & Standart Sapma & 4.32 & 3.72 \\
\hline & Çarpıklık & 0.95 & 0.80 \\
\hline \multirow{3}{*}{2007} & Ortalama & 7.52 & 7.80 \\
\hline & Standart Sapma & 5.90 & 6 \\
\hline & Çarpıklık & 2.00 & 3.66 \\
\hline \multirow{3}{*}{2008} & Ortalama & 7.00 & 6.45 \\
\hline & Standart Sapma & 3.71 & 3.98 \\
\hline & Çarpıklık & 0.29 & 1 \\
\hline \multirow{3}{*}{2009} & Ortalama & 7.45 & 7.64 \\
\hline & Standart Sapma & 5.84 & 6.18 \\
\hline & Çarpıklık & 2.10 & 3.72 \\
\hline \multirow{3}{*}{2010} & Ortalama & 6.82 & 6.81 \\
\hline & Standart Sapma & 4.46 & 3.77 \\
\hline & Çarpıklık & 1.13 & 0.42 \\
\hline \multirow{3}{*}{2011} & Ortalama & 6.77 & 7.35 \\
\hline & Standart Sapma & 5.32 & 4.19 \\
\hline & Çarpıklık & 1.48 & 1.41 \\
\hline \multirow{3}{*}{2013} & Ortalama & 7.42 & 7.27 \\
\hline & Standart Sapma & 5.33 & 3.77 \\
\hline & Çarpıklık & 5.01 & 1.99 \\
\hline \multirow{3}{*}{2014} & Ortalama & 7.77 & 8.21 \\
\hline & Standart Sapma & 4.32 & 3.72 \\
\hline & Çarpıklık & 0.95 & 0.80 \\
\hline \multirow{3}{*}{2015} & Ortalama & 6.53 & 6.79 \\
\hline & Standart Sapma & 3.95 & 3.23 \\
\hline & Çarpıklık & 1.07 & 0.93 \\
\hline
\end{tabular}


Saniye DEMIR ve Ark.

Çizelge 5. Yıllık yağı̧s verilerinin normalite analizleri

\begin{tabular}{lccccccccccc}
\hline Yillar & $\mathbf{2 0 0 5}$ & $\mathbf{2 0 0 6}$ & $\mathbf{2 0 0 7}$ & $\mathbf{2 0 0 8}$ & $\mathbf{2 0 0 9}$ & $\mathbf{2 0 1 0}$ & $\mathbf{2 0 1 1}$ & $\mathbf{2 0 1 2}$ & $\mathbf{2 0 1 3}$ & $\mathbf{2 0 1 4}$ & $\mathbf{2 0 1 5}$ \\
\hline M-W & 0.900 & 0.086 & 0.994 & 0.737 & 0.952 & 0.491 & 0.720 & 0.136 & 0.600 & 0.123 & 0.381 \\
\hline K-S & 0.876 & 0.884 & 0.476 & 0.535 & 0.189 & 0.400 & 0.151 & 0.053 & 0.396 & 0.160 & 0.734 \\
\hline
\end{tabular}

\section{SONUÇ}

Tokat ili 2005-2016 yılları arasındaki yă̆ı̧̧ verilerinin CLIGEN iklim modeli ile simüle edildiği çalışmada modelin performansı değerlendirilmiştir. Bunun için yağışlar günlük, aylık ve yıllık olarak gruplandırılmıştır.

Model günlük yağışları, aylık ve yıllık yağışlara göre daha düşük bir performans ile tahmin etmiştir. Çalışma performansı mükemmel olmamakla beraber kabul edilebilir düzeydedir.

\section{KAYNAKLAR}

Anonim. 2015. Tokat iklim verileri. Metereoloji Genel Müdürlüğü. 2015.

Elliot WJ, Arnold, CD, 2001. Validation of the weather generator CLIGEN with precipitation data from Uganda. Trans. ASAE 44 (1):53-58.

Fan JC, Yang CH, Li, CH, Huang, HY,2013. Assessment and validation of CLIGEN-simulated rainfall data for Northern Taiwan. Paddy Water Environ 11:161-173.

Headrick MG, Wilson B N, 1997. An evaluation of stochastic weather parameters for Minnesota and their impact on WEPP. ASAE paper no. 972230. St. Joseph, Mich: ASAE.

Johnson GL, CL, Hanson SP, Ballard BE, 1996. Stochastic weather simulation: Overview and analysis of two commonly used models. J. Appl. Meteorol., 35(1), 1878-1896.

Jones JW, Hoogenboom G, Porter CH, Boote KH and 6 others, 2003. The DSSAT cropping system model. Eur. J. Agron., $18,235-265$.

Kou XG, Jianping Y, Wang CZ, 2007. Validation of the weather generator CLIGEN with daily precipitation data from the Loess Plateau. J. Hydrol. 347(3-4), 347-357.

Mann HB, 1945. Nonparametric tests against trend. Econometrica 13:245-259.

Min YM, Kryjov VN, An KH, Hameed, SN Sohn SJ, Lee WJ, Oh JH, 2011. Evaluation Of the weather generator CLIGEN with daily precipitation characteristics in Korea. The Korean Meteorological Society And Springer, 47(3), Pp.255-263.
Aylık toplam yağışları tahmin etmedeki başarısı, günlük ve yıllık yağışlara göre çok yüksektir. Yağış değerleri birbirine çok yakındır ve aralarında önemli bir fark yoktur. Yıllık toplam yağışları tahmin etmede de oldukça yüksek bir performans göstermiştir. Yıllık toplam yağış verileri birbirine yakındır. Gerek aylık gerekse yıllık yağışlarda ekstrem değerler daha normal seviyeye yaklaştı̆̆ından, modelin bu yağışları simüle etme başarısı artmaktadır.

Nearing MA, Foster GR, Lane LJ and Finkner SC, 1989. A process-based soil erosion model for USDA-Water Erosion Prediction Project technology. (1n press) Transactions of the ASAE.

Nicks AD, Lane LJ, Gander GA, 1995. USDA-Water Erosion Prediction Project: Hillslope profile and watershed model documentation. 2.1-2.22. NSERL report no. 10. Flanagan, D.C., Nearing, M.A (ed) West Lafayette Ind: USDA-ARS National Soil Erosion Reserach Laboratory.

Soil Survey Staff, 2009. R. Burt (ed.). Soil survey field and laboratory methods manual. Ver. 1.0. USDA/NRCS, Soil Survey Investigations Report No. 51. Available online at http://www.soils.usda.gov/technical/ (verified January 24, 2011).

Wilks DS, 1999. Multisite downscaling of daily precipitation with a stochastic weather models. Prog. Phys. Geog. 23, 329-357.

Zhang XC, Garbrecht JD, 2003. Evaluation of CLIGEN precipitation parameters and their implication on WEPP runoff and erosion prediction. Trans. ASAE, 46, 311-320.

Zhang XC, Garbrecht JD, 2007. A comparision of explicit and implicit spatial downscaling of GCM output for soil erosion and crop production assaessments. Climatic Change, $84,337-363$. 